\title{
Testing the Reliability of Flexible MOX Gas Sensors under Strain ${ }^{\dagger}$
}

\author{
M. Alvarado ${ }^{1}$, A. Romero ${ }^{1}$, J.L. Ramírez ${ }^{1, *}$, S. De la Flor ${ }^{2}$ and E. Llobet ${ }^{1}$ \\ 1 MINOS-EMaS, Departament d'Enginyeria Electrònica, Elèctrica i Automàtica, Universitat Rovira i Virgili, \\ 43007 Tarragona, Spain; miriam.alvarado@urv.cat (M.A.); alfonso.romero@urv.cat (A.R.); \\ eduard.llobet@urv.cat (E.L.) \\ 2 Departament d'Enginyeria Mecànica, Universitat Rovira i Virgili, Av. Països Catalans 26, 43007 Tarragona, \\ Spain; silvia.delaflor@urv.cat \\ * Correspondence: joseluis.ramirez@urv.cat \\ + Presented at the 8th GOSPEL Workshop, Gas Sensors Based on Semiconducting Metal Oxides: Basic \\ Understanding \& Application Fields, Ferrara, Italy, 20-21 June 2019.
}

Published: 19 June 2019

\begin{abstract}
We present flexible chemo-resistive sensors based on AACVD grown tungsten trioxide $\left(\mathrm{WO}_{3}\right)$ nanowires. The sensor response to gases, before and after a 50-cycle bending test, is reported. Thus, proving that reliable gas sensors, able to withstand repeated bending, have been achieved. Moreover, their integrity and durability have been tested under harsh bending conditions until break down.
\end{abstract}

\section{Background}

Flexible sensors are a promising technology for personal environmental monitoring, sports or healthcare and medicine. These applications involve using wearables, which are attached to the body or clothes to sense different variables, including gases. The use of flexible substrates improves the performance in these systems [1]. However, usually, little or no information is given on reliability. Here, metal oxide nanowire gas sensors over polymeric foil, have been developed and their performance after repeated mechanical stress test has been evaluated.

\section{Materials and Methods}

The sensor architecture consists of one electrode and one coplanar heater over a polymeric substrate (Kapton ${ }^{\circledR} 50.5 \mu \mathrm{m}$ thick) as used in [2]. There is a layer of $\mathrm{WO}_{3}$ nanowires coating the active area (Figure 1). Electrode and heater patterns were stenciled using silver ink as reported in [3]. The $\mathrm{WO}_{3}$ layer was grown directly on the flexible substrate via an aerosol assisted chemical vapor deposition in a hot $\left(350^{\circ} \mathrm{C}\right)$ wall reactor. Precursors used were tungsten hexacarbonyl dissolved in a mixture of acetone and methanol, as reported in [4].
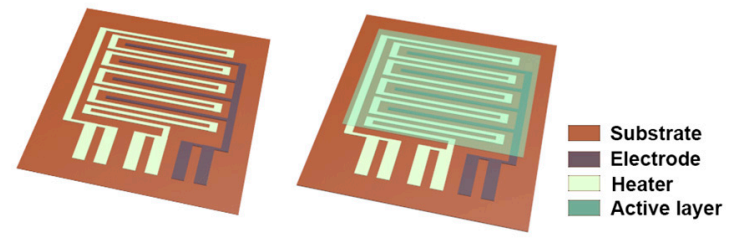

Figure 1. Device layout. Left: electrode and heater. Right: active layer over both elements. Device size $14 \times 14 \mathrm{~mm}^{2}$. 
We made a controlled bending test using an electromechanical universal testing machine (Shimadzu AGS-X $10 \mathrm{kN}$ ). Sensors were strained up to $15 \%$ and the maximum deflection due to buckling was $\mathrm{d}=3.23 \mathrm{~mm}$. The test consisted of 50 continuous moves of the upper grip. Each move was $2 \mathrm{~mm}$ down and up, at $20 \mathrm{~mm} / \mathrm{min}$, producing a curvature radius of approx. $3.1 \mathrm{~mm}$ (Figure 2). Meanwhile, the electrical resistance of the active layer, the stroke and the force applied were measured.

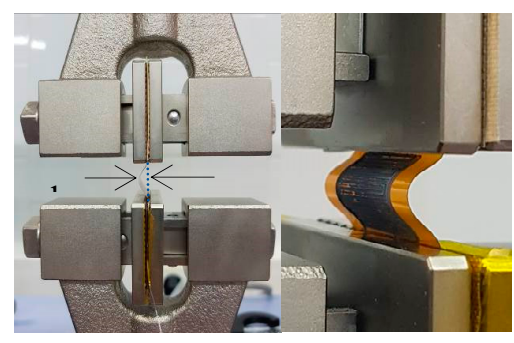

Figure 2. Universal testing machine grips holding the sensor. $\mathrm{d}=$ maximum deflection distance.

\section{Results}

The AACVD process resulted in the direct growth onto the transducer of $\mathrm{WO}_{3}$ nanowires (150 $\mathrm{nm}$ in diameter and 10 microns in length). Sensors were tested against $\mathrm{H}_{2}$ before and after the bending test. In both cases, three cycles of three $\mathrm{H}_{2}$ concentrations (250, 500 and 750 ppm) were tested, at a heater mean temperature of $150{ }^{\circ} \mathrm{C}$. Sensor response after the bending test (Figure 3 ) shows small changes (after bending test baseline electrical resistance increased by $5.5 \%$ Figure 4 , which can be easily calibrated). An additional test was carried out until the sensing layer was damaged: the electrical resistance increased significantly at zero stroke. This occurred after 200 bending cycles: 100 under compressive strain and 100 under tension strain, with a shift of $4 \mathrm{~mm}$ and $\mathrm{d}=4.3 \mathrm{~mm}$ of maximum deflection (curvature radius $3.2 \mathrm{~mm}$ ).

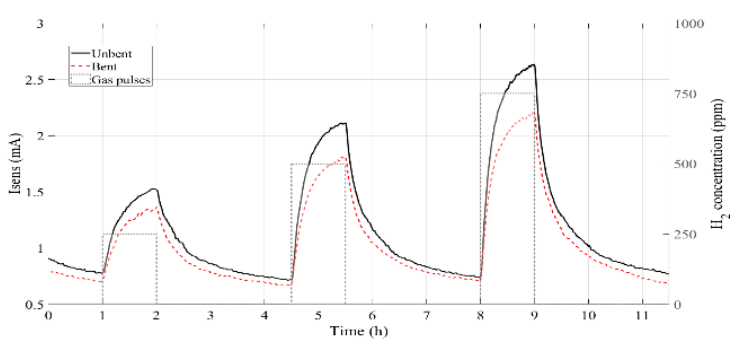

(a)

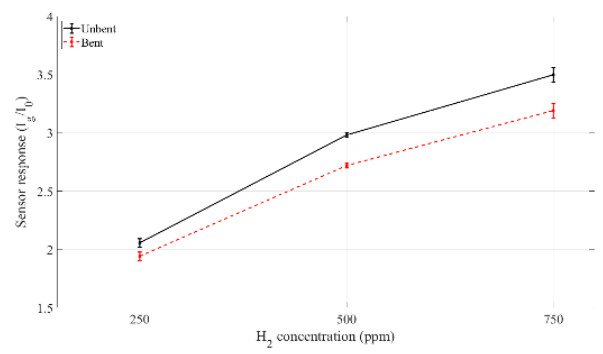

(b)

Figure 3. (a) Current through active layer at different concentrations of $\mathrm{H}_{2}\left(250,500\right.$ and $\left.750 \mathrm{ppm} \mathrm{H}_{2}\right)$ and (b) Sensor response to $\mathrm{H}_{2}$ concentration, before and after 50 repeated bending tests.

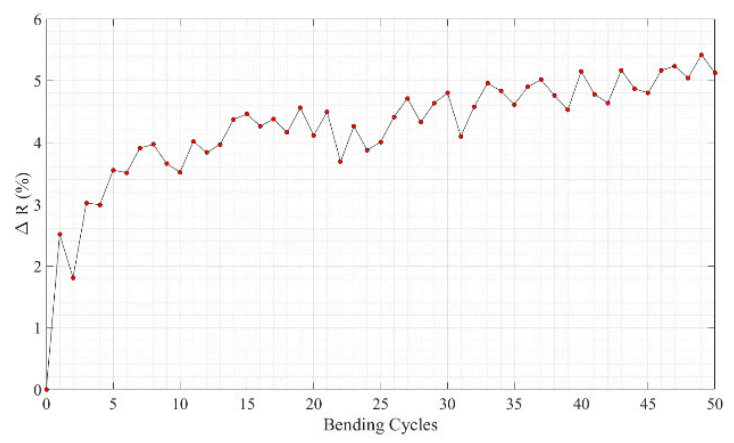

Figure 4. Percentage of sensor resistance increase during 50-cycles bending test. 


\section{Conclusions}

We have proved that is possible to produce reliable flexible sensors with a very affordable technology. After a 50-cycles bending test, under tensile strain, sensor response remains almost unchanged. Moreover, the limits of the physical system have been tested under harsh bending conditions. The sensors could withstand up to 200 bending cycles before losing functionality. This is being developed further via the design of in-house made metal oxide inks for achieving fully printed functional devices. Characterization results will be presented at the conference.

Funding: This research was funded in part by MINECO and FEDER under grant no. TEC2015-71663-R and by AGAUR under grant no. 2017 SGR 418.

Conflicts of Interest: The authors declare no conflict of interest. The funders had no role in the design of the study; in the collection, analyses, or interpretation of data; in the writing of the manuscript, or in the decision to publish the results.

\section{References}

1. Nag, A.; Mukhopadhyay, S.C.; Kosel, J. Wearable flexible sensors: A review. IEEE Sens. J. 2017, 17, 3949.

2. Ramírez, J.L.; Annanouch, F.E.; Llobet, E.; Briand, D. Architecture for the efficient manufacturing by printing of heated, planar, resistive transducers on polymeric foil for gas sensing. Sens. Actuators B Chem. 2018, 258, 952-960.

3. Alvarado, M.; Navarrete, E.; Romero, A.; Ramírez, J.L.; Llobet, E. Flexible Gas sensors employing octahedral indium oxide films. Sensors 2018, 18, 999.

4. Vallejos, S.; Umek, P.; Blackman, C. Aerosol assisted chemical vapour deposition control parameters for selective deposition of tungsten oxide nanostructures. J. Nanosci. Nanotechnol. 2011, 11, 8214-8220.

(C) 2019 by the authors. Licensee MDPI, Basel, Switzerland. This article is an open access article distributed under the terms and conditions of the Creative Commons Attribution (CC BY) license (http://creativecommons.org/licenses/by/4.0/). 